\title{
Network Modeling and Dynamic Mechanisms of Multi-Hazards-A Case Study of Typhoon Mangkhut
}

\author{
Yilong Niu ${ }^{1,2}{ }^{-}$, Jiayi Fang ${ }^{1,2,3, *}$, Ruishan Chen ${ }^{1,2,3, * \mathbb{C}}$, Zilong Xia ${ }^{1,2}$ and Hanqing $X^{1,2}$ \\ 1 Key Laboratory of Geographic Information Science (Ministry of Education), East China Normal University, \\ Shanghai 200241, China; 52173901007@stu.ecnu.edu.cn (Y.N.); xiazilong_2008@126.com (Z.X.); \\ xuhq@stu.ecnu.edu.cn (H.X.) \\ 2 School of Geographic Sciences, East China Normal University, Shanghai 200241, China \\ 3 Institute of Eco-Chongming, East China Normal University, Shanghai 200241, China \\ * Correspondence: jyfang@geo.ecnu.edu.cn (J.F.); rschen@geo.ecnu.edu.cn (R.C.)
}

Received: 30 June 2020; Accepted: 1 August 2020; Published: 5 August 2020

check for updates

\begin{abstract}
Coastal areas are home to billions of people and assets that are prone to natural disasters and climate change. In this study, we established a disaster network to assess the multi-hazards (gale and heavy rain) of typhoon disasters, specifically Typhoon Mangkhut of 2018 in coastal China, by applying the methodology of a bipartite network in both time dimension and spatial dimension. In this network, the edge set and adjacent matrix are based on the connection between an hour and a city with a multi-hazards impact that includes gales and heavy rain. We analyze the characteristics and structure of this disaster network and assess the multi-hazards that arose from Typhoon Mangkhut in different areas. The result shows that there are 14 cities in the core area and 21 cities in the periphery area, based on core-periphery classification in the disaster network. Although more damage area belongs to the periphery area, the percentage of the population affected by the typhoon and direct economic loss in GDP in the core area was $69.68 \%$ and $0.22 \%$ respectively, which is much higher than in the periphery area $(55.58 \%$ and $0.06 \%$, respectively) The core area suffered more from multi-hazards and had more disaster loss. This study shows that it is feasible to assess multiple hazards with a disaster network based on the bipartite network.
\end{abstract}

Keywords: compound extreme events; multi-hazards assessment; bipartite network; Typhoon Mangkhut

\section{Introduction}

Natural hazards have tremendous impacts on socio-ecological systems [1]. It was reported that $75 \%$ of the world's population has been exposed to potentially fatal natural disasters, such as earthquakes, tropical cyclones (TCs), and floods, or droughts, with more than 184 deaths per day recorded between 1980 and 2000 [2]. Moreover, "extreme weather events", "failure of climate-change mitigation and adaption", and "natural disaster" are the top three global risks, in terms of likelihood, in 2019 [3]. For example, there were approximately 230 thousand deaths in 14 countries during the 2004 India Ocean tsunami; Hurricane Katrina in 2005 led to more than USD 100 billion in damages and 1300 deaths; Hurricane Sandy in 2012 led to over USD 50 billion in damages [4-6]. Multi-hazards would lead to a more significant impact on human society and the earth system than a single hazard [7]. Recently, a series of studies have focused on multi-hazards and compound extreme events. Aryal et al. [8] analyzed the contribution of North Atlantic tropical cyclones to flooding and heavy rainfall in the United States, with annual maxima and peaks-over-threshold, and showed that TCs contribution to $20 \% \sim 30 \%$ of annual maximum flood events over Florida and coastal areas of the Eastern United States. Wahl et al. [9] focused on the compound flooding from storm surges and heavy precipitation and showed that the risk of compound flooding is higher than every single hazard; 
meanwhile, the number of compound events has increased during the past century at many of the major coastal cities in the United States. Understanding multi-hazards and compound extreme events is necessary and important for scientists, decision-makers, and the public to mitigate related risks under the complicated situation. Evaluation of compound extreme events would lead to further insight into disaster research for the future [10].

As a typical compound extreme hazard, the tropical cyclone poses a high natural disaster risk in coastal areas [11-13]. Approximately 1.2 billion people live in coastal areas (23\% of the world's population), with $10 \%$ of the world's population and $13 \%$ of the world's urban population living in the Low Elevation Coastal Zone, which is defined as the contiguous area along the coast that is less than $10 \mathrm{~m}$ above sea level [14-16]. These areas are particularly influenced by natural hazards, such as coastal flooding, tropical cyclones, and sea-level rise, which result in secondary disasters like storm surges, landslides, strong wind, and heavy precipitation $[17,18]$. Therefore, it is necessary to invest in coastal hazard mitigation measures and reduce disaster risks to coastal areas, for coastal environment preservation [19]. Between 1949 and 2010, there were 2074 tropical cyclones generated from the Western North Pacific, with 765 of them landing on Chinese coastal areas [20]. More than 3 million $\mathrm{km}^{2}$ and $70 \%$ of large and developmental cities are located in the coastal areas of China [21]. Thus, the interaction of all of these factors (multi-hazards, secondary disasters, and high exposure) would likely lead to a huge risk for Chinese coastal areas, and with the rate of development and urbanization in China under prospective climate-change scenarios, the risk of natural disasters to coastal areas in China would likely increase rapidly [22]. Meanwhile, urbanization in coastal areas has brought huge physical changes to urban water cycle systems, land-use change in urban areas, and the loss in the previous surface reduced the infiltration into soils [23]. Even with artificial drainage infrastructure, the increasing runoff may induce a higher urban flood risk, especially under a heavy-rain scenario [24].

Nowadays, scientists and researches focus on multi-hazards and secondary disasters in coastal areas that attribute to tropical cyclones, based on both observation and model simulation, with historical records and climate-change scenarios. For instance, Zhang et al. [25] employed two different coastal assessment models to evaluate the storm surge flooding induced by a hurricane on the coast of South Florida. Lin et al. [26] indicated that the flooding hazard in New York City has increased significantly over the past two centuries and would increase rapidly until the end of the 21st century, due to changes in storm surges and sea level in the future. Ye and Fang [27] estimated the compound hazards of tropical cyclones in China and found that copula function could provide an effective method to investigate the compound hazards. Gettelman et al. [28] presented an ensemble simulation of tropical cyclone damage based on a high-resolution global climate model and found that global storm damage in 2070 would increase by $50 \%$ over 2015. Tsuboki et al. [29] predicted that the intensity of super-typhoons would increase in the late 21century. However, some scientists insist that the results of a tropical cyclone analysis could not provide reliable evidence-based on historical records and climate models [30]. Therefore, for acquiring dependable results in the influence of tropical cyclones across coastal areas based on scientific methodologies of multi-hazard assessment, we need to study the influence of tropical cyclones in coastal zones based on a multi-hazard assessment.

To solve the problems of multi-hazards in tropical cyclones, many scientists and researchers focus on multi-hazards' assessment based on qualitative and quantitative analysis [31-34]. Among an array of methodologies reviewed in Kappes et al. [35], there are many different kinds of multi-hazard assessment methodologies that focus on various challenges, such as multifactor analysis, system dynamics, probabilistic models, joint probability distributions, and complex networks [36-40]. Compared with other methodologies, a complex network is a useful tool which could build the relationship easily between each component in complex systems in the real world. In recent years, complex networks have been employed in many hazards and disaster studies around the world, such as for extreme rainfall, earthquakes, droughts, flooding, and forest fires [37,41-45]. However, a complex network still needs to be established for tropical cyclone assessment, to discover the dynamic mechanism of disaster evolution and the interactive relationship between different relevant hazards factors such as 
gale, heavy precipitation, flooding, storm surges, and sea-level rise. In this study, the bipartite network, which is a special type of complex network, was employed, to analyze multi-hazards impacted by Typhoon Mangkhut in China in 2018.

For this case study, the online data of best track record and hourly precipitation remote sensing data were collected and used to employ the bipartite network to establish the connection between time and space. To realize multi-hazard assessment, we coupled two different kinds of hazards, gale and heavy precipitation, as important drivers of network construction. The primary objectives of this study were to (1) establish a scientific network of typhoon system which could describe the dynamic mechanisms of Typhoon Mangkhut accurately based on interactions between different natural hazards and different scales and (2) find the time and areas which were most impacted by multi-hazards from Typhoon Mangkhut, with an efficient and precise assessment method.

\section{Materials and Methods}

\subsection{Super Typhoon Mangkhut}

Super Typhoon Mangkhut generated from the Western North Pacific on 7 September 2018. It swept across the Philippines and landed in China on 16 September 2018. It was the second most intense storm that impacted Hong Kong since 1946 [46]. There were more than 100 deaths in the Philippines until 18th September 2018 [47], and at least 458 people were injured. More than 60,000 fallen trees were reported and over 40,000 households in Hong Kong were interrupted [48]. Typhoon Mangkhut was characterized by its maximum wind speed of $287 \mathrm{~km}$ per hour and its large diameter of the gale, reaching $1300 \mathrm{~km}$ wide and moving $6550 \mathrm{~km}$ (Figure 1). Compared with other tropical cyclones in 2018, Typhoon Mangkhut was the most powerful [49]. Large areas in China and the Philippines were influenced by strong winds and heavy precipitation that resulted from Mangkhut.

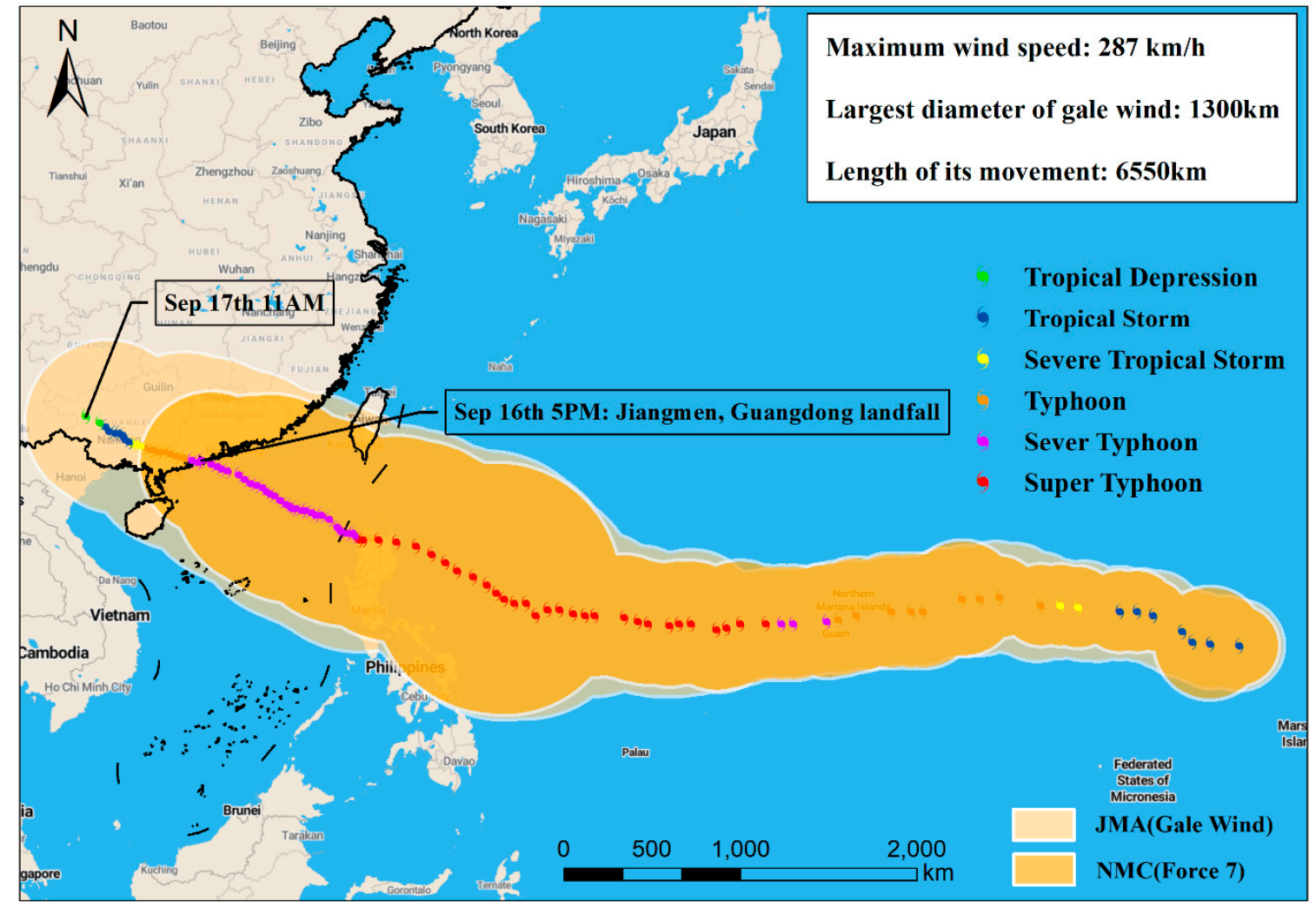

Figure 1. Best track map of the Typhoon Mangkhut. Note: The time zone here is UTC +8 . 


\subsection{Study Areas}

Thirty-five cities in Southern China that were impacted by both gale winds and heavy precipitation during Typhoon Mangkhut were selected as study areas. These included 21 cities in Guangdong, nine cities in Guangxi, one city in Hunan, one city in Jiangxi, one city in Hainan, Hong Kong, and Macao (Figure 2).

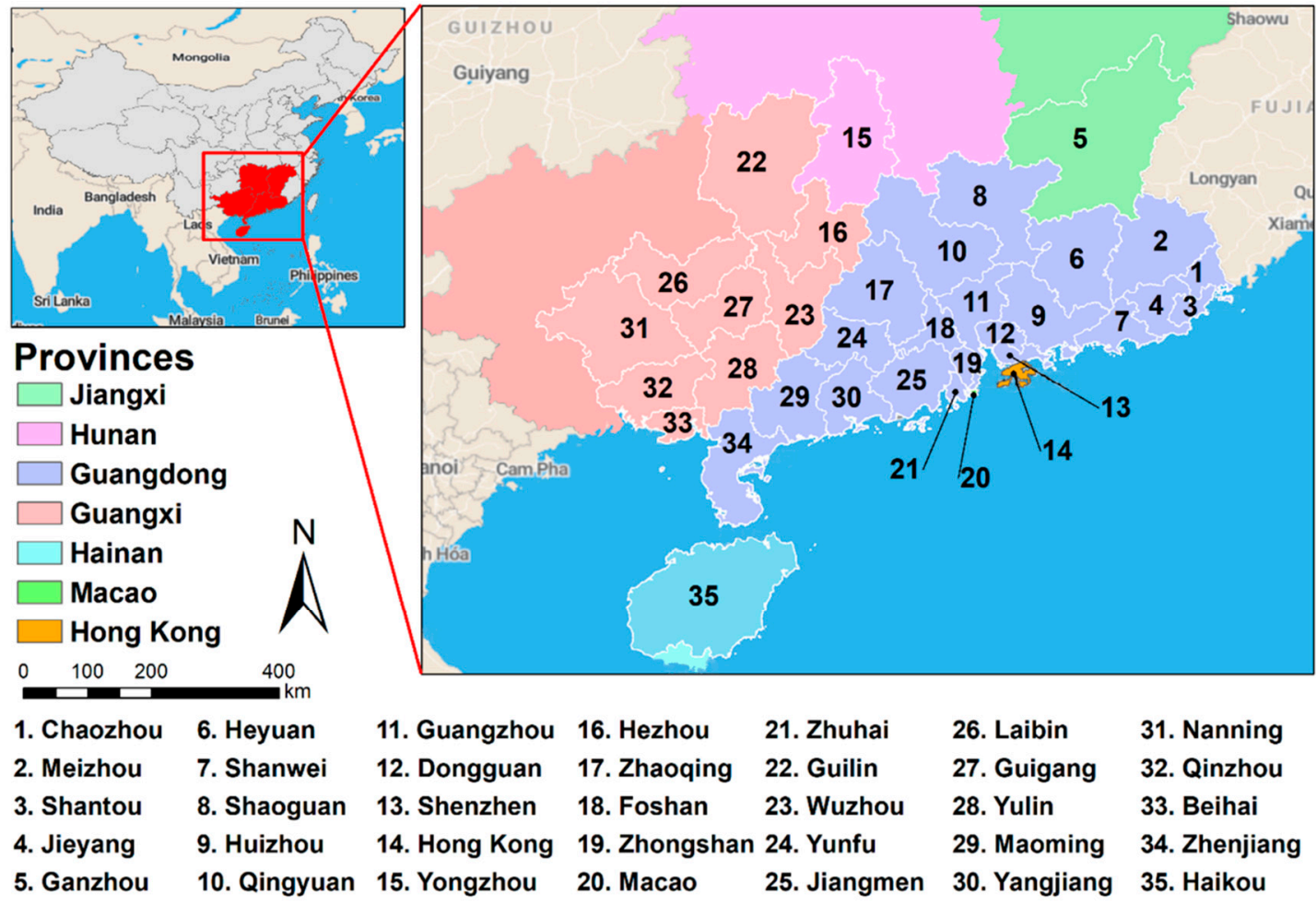

Figure 2. Study areas affected by the Typhoon Mangkhut in China.

\subsection{Dataset}

The observed best track record and forecasting record of Typhoon Mangkhut was collected from an online dataset, which was published by the National Meteorological Center of China Meteorological Administration (NMC) and Japan Meteorological Agency (JMA). These records include time, location of typhoon center, wind speed, central pressure, moving direction and speed of typhoon, and affected range of different wind levels. However, NMC would not calculate the affected range of different wind levels since tropical cyclone landfall; therefore, the data from JMA were used, as well. Figure 1 shows the detailed hourly information of the affected range of Typhoon Mangkhut.

Hourly precipitation data were collected from the Global Satellite Mapping of Precipitation (GSMaP) dataset, which was published on Google Earth Engine. The values of hourly precipitation rate in GSMaP were estimated using multi-band passive microwave and infrared radiometers from the GPM Core Observatory satellite, with the assistance of a constellation of other satellites. The spatial resolution is $0.1 \times 0.1$ degree [50,51]. The grid-cell data of hourly precipitation rate in the study area were collected, and those grids which represented heavy rain were selected. Here we employ the definition from a glossary of meteorology from the American Meteorological Society, which defines "heavy rain" as having a precipitation rate of over $7.6 \mathrm{~mm}$ per hour. Figure 3 shows the detailed information of hourly precipitation in the study area; the time zone in this research is UTC +8 . 

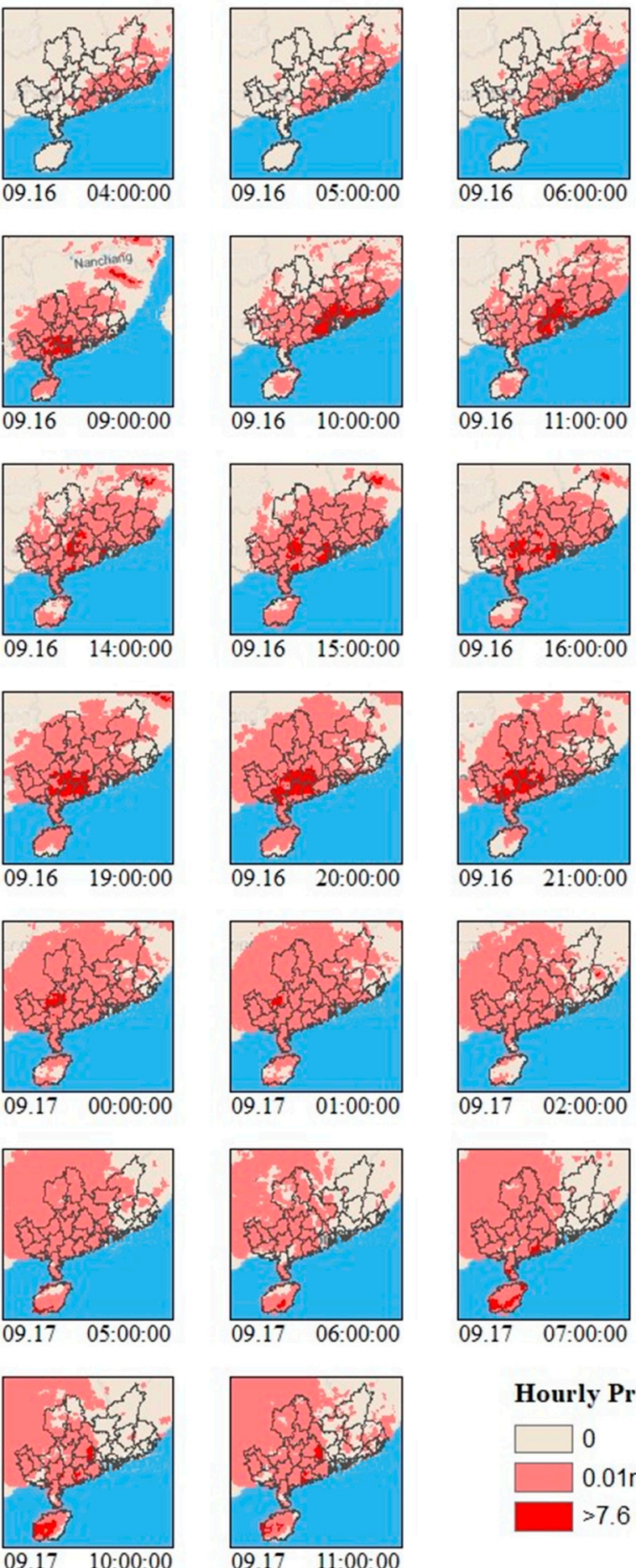
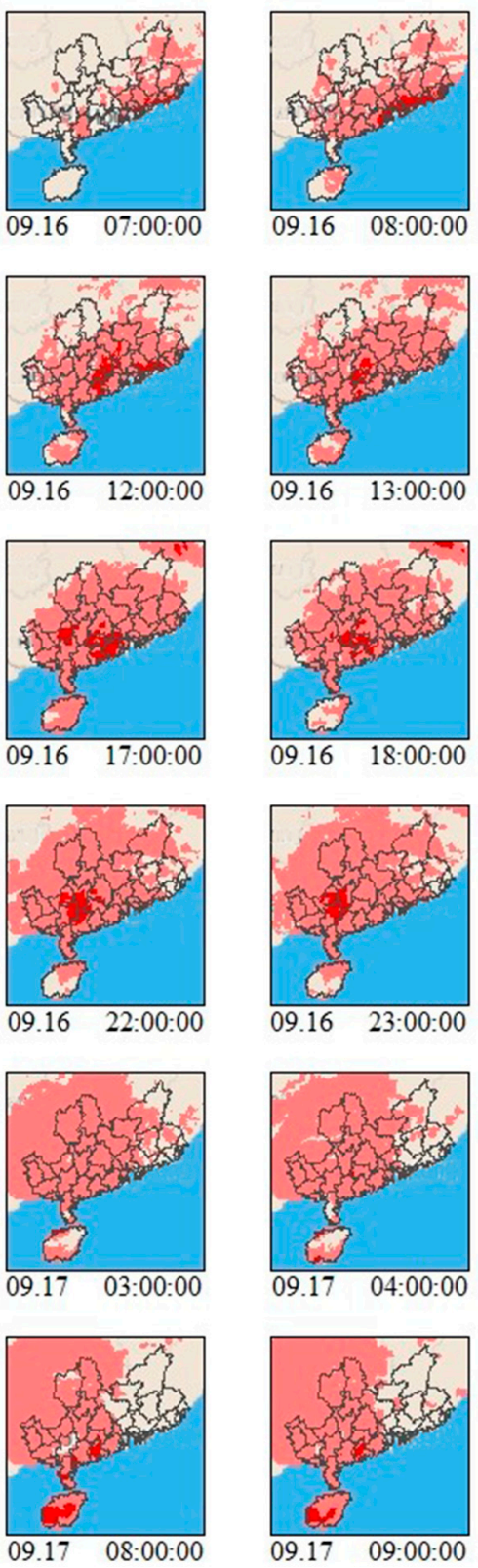

\section{Hourly Precipitation}
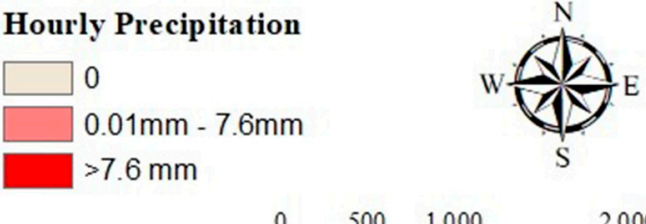

2,000

Figure 3. Hourly precipitation schematic of the Typhoon Mangkhut, in China, from 16 September to 17 September.

Disaster damage records of the Typhoon Mangkhut were collected from the China National Commission for Disaster Reduction. These records included the affected areas, affected population (e.g., transferred, missing, and death), agricultural loss, house collapse, and direct economic loss. 


\subsection{Methodology}

With the development of random graphs [52], complex networks that describe a variety of systems with large amounts of elements and complicated relationships have enticed many scientists' attention in different research fields [53]. This methodology, which is between regular graphs and random graphs, focused on illustrating the structure and mechanism of system and network in the real world, and it has been employed in many practical systems analyses, such as the World Wide Web [54], disease transmission systems [55], ecological networks [56], and cellular networks [7]. Additionally, as a special type of complex network, the bipartite network is also employed by many research fields, such as the movie actor collaboration network and science collaboration system [57]. Compared with the classical complex network, the bipartite network has two kinds of nodes, and the connection could only be built in different kinds of nodes. Additionally, in order to assess the characteristics of a network, such as degree distribution, clustering coefficient, and small-world nature, some traditional methods would be employed to transform the two-mode network into the one-mode network [58].

To build and visualize the bipartite network in this research, researchers developed a useful software focused on social network analysis called "The University of California at Irvine NETwork" (UCINET) [59]. The input information of UCINET could be saved as a matrix format and invoked by different evaluating modules, such as multidimensional scaling, correspondence analysis, factor analysis, and multiple regression. Another useful module in UCINET is NetDrew, which can visualize the nodes and edges of the network from matrix format.

The main steps for disaster network construction based on input datasets and bipartite network framework are presented in Figure 4. The primary purpose of the construction is to discover the dynamic mechanism of Typhoon Mangkhut and evaluate the targeted cities that were influenced by multi-hazards efficiently and scientifically. The main steps are as follows: (1) coupling gale hazard data from the best track dataset with heavy rain hazard data from hourly precipitation dataset; (2) establishing a disaster network based on the multi-hazards data and basic information of cities; (3) analyzing the characteristics and features of the disaster network, such as network density, clustering coefficient, and small-world nature; and (4) evaluating disaster loss of the Typhoon Mangkhut based on the disaster network and observed disaster damage records.

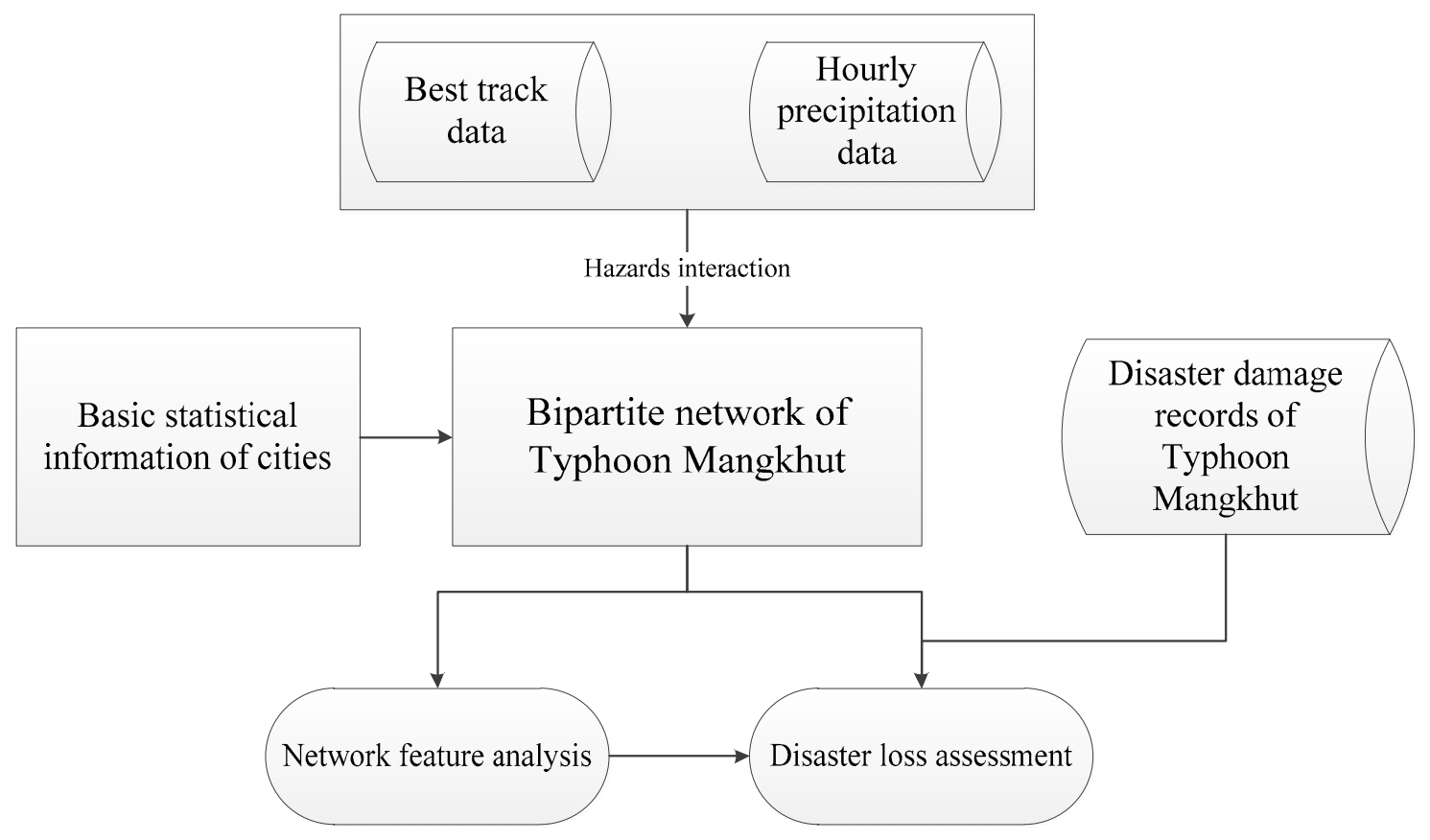

Figure 4. Flowchart of the disaster network construction in this study. 


\subsubsection{Rules to Establish the Bipartite Network}

There are two different kinds of nodes that belong to two disjointed sets in the bipartite network. For the disaster network of the Typhoon Mangkhut, one kind of node (Ti) represents each hour (Time Set, TS) and the other kind of node (Ci) represents each city (Location Set, LS). Edges could only be built between the two nodes from different sets, but each node could have many edges. For example, for each TS node, a large number of edges means that coupled hazards influenced many cities at the same time, while for each LS, a large number of edges means that this city was influenced by coupled hazards during several hours. Figure 5 shows the structure of a disaster network. This disaster network is directed and unweighted, and its one-dimensional projection of TS or LS is undirected and weighted.

Time Set

Location Set

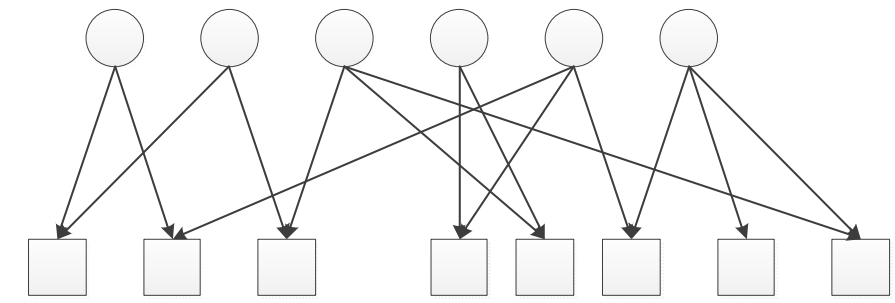

Compound hazards

(Gale and heavy rain)

Exposure units (Cities)

Figure 5. Structure of the disaster network based on bipartite network.

\subsubsection{Adjacent Matrix of Disaster Network}

To couple gales with heavy rain and establish a disaster network efficiently, we employed the adjacent matrix $\mathrm{A}=\alpha \mathrm{ij}$ to describe the disaster network and build each edge (eij), based on the following rules: (1) there is a directed edge from $\mathrm{Ti}$ to $\mathrm{Cj}$ if city $\mathrm{Cj}$ is impacted by both heavy rain (hourly precipitation rate $>7.6 \mathrm{~mm}$ ) and gale (Force 7 region before landfall or Gale Wind region after landfall) at Ti moment, and $\alpha \mathrm{ij}=1$; (2) there is no edge from Ti to $\mathrm{Cj}$ if city $\mathrm{Cj}$ is impacted by single nature hazard, or was not affected by Typhoon Mangkhut at Ti moment, and $\alpha \mathrm{ij}=0$. The disaster network of Typhoon Mangkhut is generated after building the adjacent matrix (Figure 6).

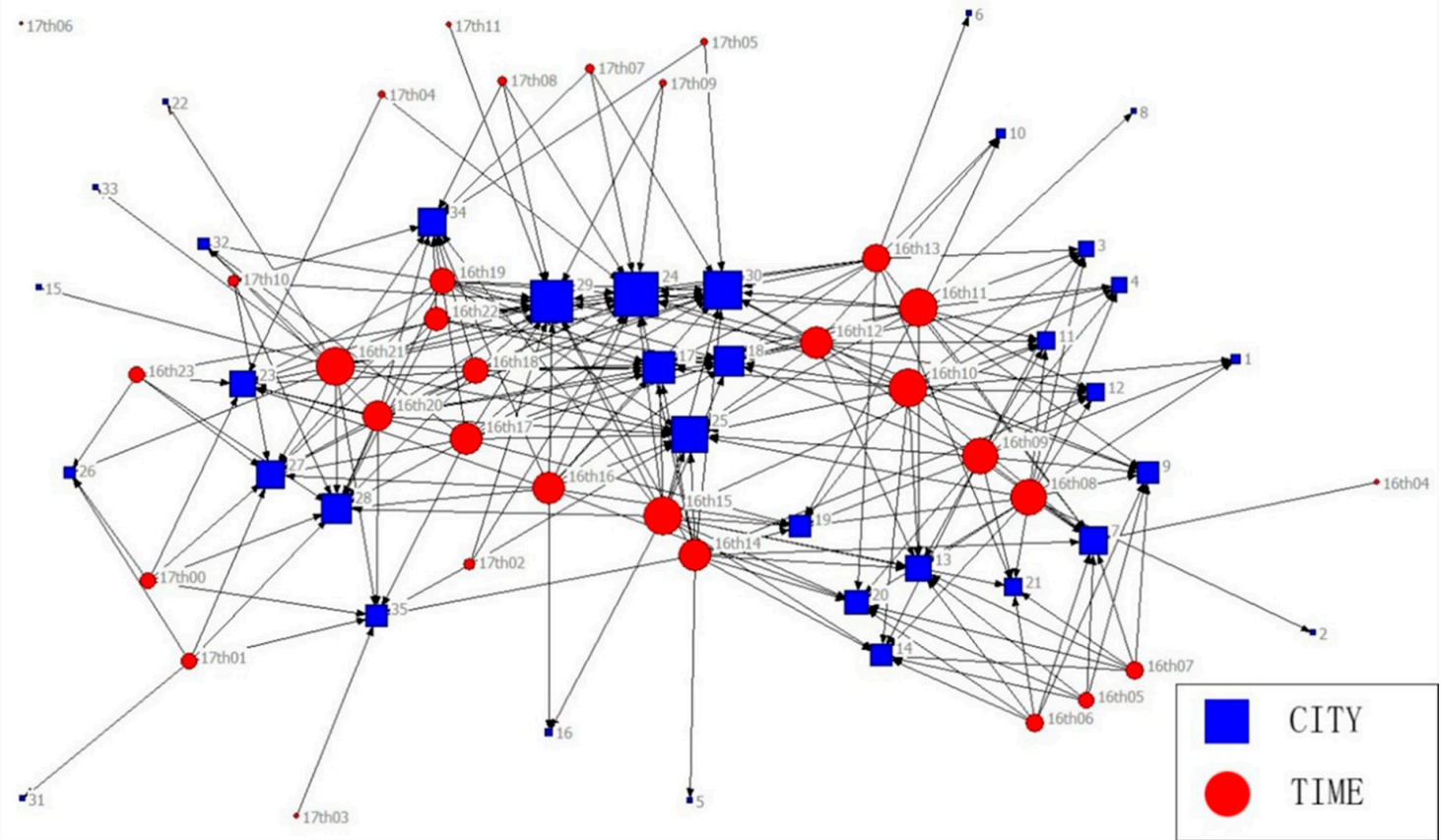

Figure 6. Visual disaster network of Typhoon Mangkhut in China. Notes: The label of a node in "Time" is created by "day+hour". For example, "17th01" means 17th September, 01:00:00. There was no city impacted by multi-hazards at 6 o'clock, 17th September. 


\section{Results}

\subsection{Analysis of Network Structure}

\subsubsection{Small World Nature}

Watts and Strogatz [60] define the small-world nature of some complex networks, which have a more significant clustering coefficient than that of a random network $(C>C$ random), and the average path length is almost as small as that of a random network ( $\mathrm{L} \approx$ Lrandom). In this research, the disaster network has a significant small-world nature in both the time (one-dimensional projection of TS) and spatial dimensions (one-dimensional projection of LS) (Table 1). For the time dimension, the overall graph clustering coefficient of the disaster network is 3.93, which is bigger than 2.38 - the value of the corresponding random network. Meanwhile, the average path length of a disaster network is 1.3, which is practically as small as 1.1 - the average path length of the corresponding random network. For the spatial dimension, the overall graph clustering coefficient of the disaster network is 3.73, which is bigger than 2.10 - the value of the corresponding random network. Moreover, the average path length of a disaster network is 1.4, which is slightly larger than 1.1-the average path length of the corresponding random network.

Table 1. Analysis result of the small-world nature of the Typhoon Mangkhut.

\begin{tabular}{lcccc}
\hline & \multicolumn{2}{c}{ Time Dimension } & \multicolumn{2}{c}{ Spatial Dimension } \\
\cline { 2 - 5 } & $\begin{array}{c}\text { Clustering } \\
\text { Coefficient (C) }\end{array}$ & $\begin{array}{c}\text { Average Path } \\
\text { Length (L) }\end{array}$ & $\begin{array}{c}\text { Clustering } \\
\text { Coefficient (C) }\end{array}$ & $\begin{array}{c}\text { Average Path } \\
\text { Length (L) }\end{array}$ \\
\hline Disaster Network & 3.93 & 1.3 & 3.73 & 1.4 \\
Random Network & 2.38 & 1.1 & 2.10 & 1.1 \\
\hline
\end{tabular}

\subsubsection{Centrality Measures}

The centrality degree (CD) of a node describes the number of other nodes that connect with a particular node. In order to compare the CD of nodes in different graphs with different scales, the normalized centrality degree (CDn), which is CD divided by the number of nodes in a network except itself (N-1), has been defined as a prominent statistic factor to analyze the importance of a node in the whole network. Figure 7 shows the result of the normalized centrality degree of each node in the disaster network, which was calculated by the two-mode centrality module in UCINET. Yunfu (24), Maoming (29), Yangjiang (30), Jiangmen (25), and Zhaoqing (17) had a higher normalized centrality degree (bigger than 0.4), meaning that multi-hazards impacted these cities for a longer time. In addition, there is a "peak time period", which includes 15 nodes (hour) from 08h00 to $22 \mathrm{~h} 00$ on 16th September 2018 that had a higher normalized centrality degree (bigger than 0.25), meaning that, during these hours, many cities suffered from multi-hazards impact.

\subsubsection{Core-Periphery Analysis}

We could pick up the "the most impacted" cities and time based on normalized centrality degree analysis. However, to analyze the multi-hazards' impact systematically and investigate the relationship between time and space, a traditional method called two-mode core-periphery analysis was employed in this research. The core-periphery structure is an ideal-typical pattern that divides both the rows and the columns into two classes, and the numerical search method used by the two-mode core-periphery module is a genetic algorithm [59]. The "core" section of the two-mode network is different from the kernel of nodes in TS or LS, as it is a cluster of frequently co-occurring times and cities. The core-periphery analysis showed that Dongguan (12) has a smaller centrality degree than Huizhou (9). However, Dongguan was impacted mostly in time and therefore is classified as core, while Huizhou is classified as periphery. Figure 8 shows the matrix of core-periphery classification. 
There are nine cities of Guangdong Province, three cities of Guangxi Province, and one city of Hainan Province in the core block, while the time series from 08h00 to $11 \mathrm{~h} 00$ and from $13 \mathrm{~h} 00$ to $21 \mathrm{~h} 00$ on 16th September are the kernel nodes in the core block. The calculated density shows that there is a significant core-periphery structure in the disaster network of Typhoon Mangkhut, based on the comparison between 0.60 and 0.05 . Figure 9 shows the classification of different areas, disaster damage record of Typhoon Mangkhut in these areas, and economic statistics of these areas in 2016.

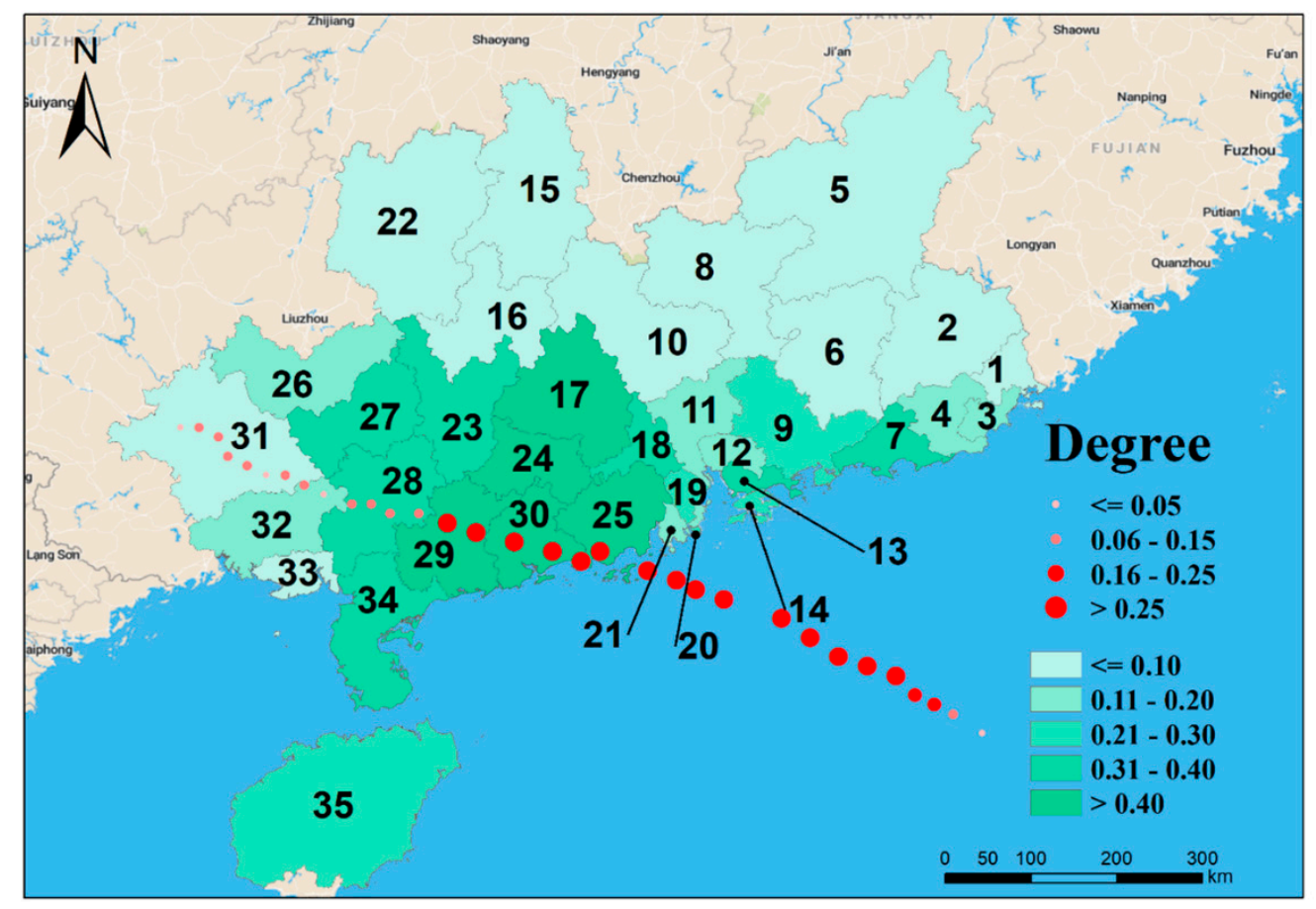

Figure 7. Normalized centrality degree of disaster network in different cities and different times.

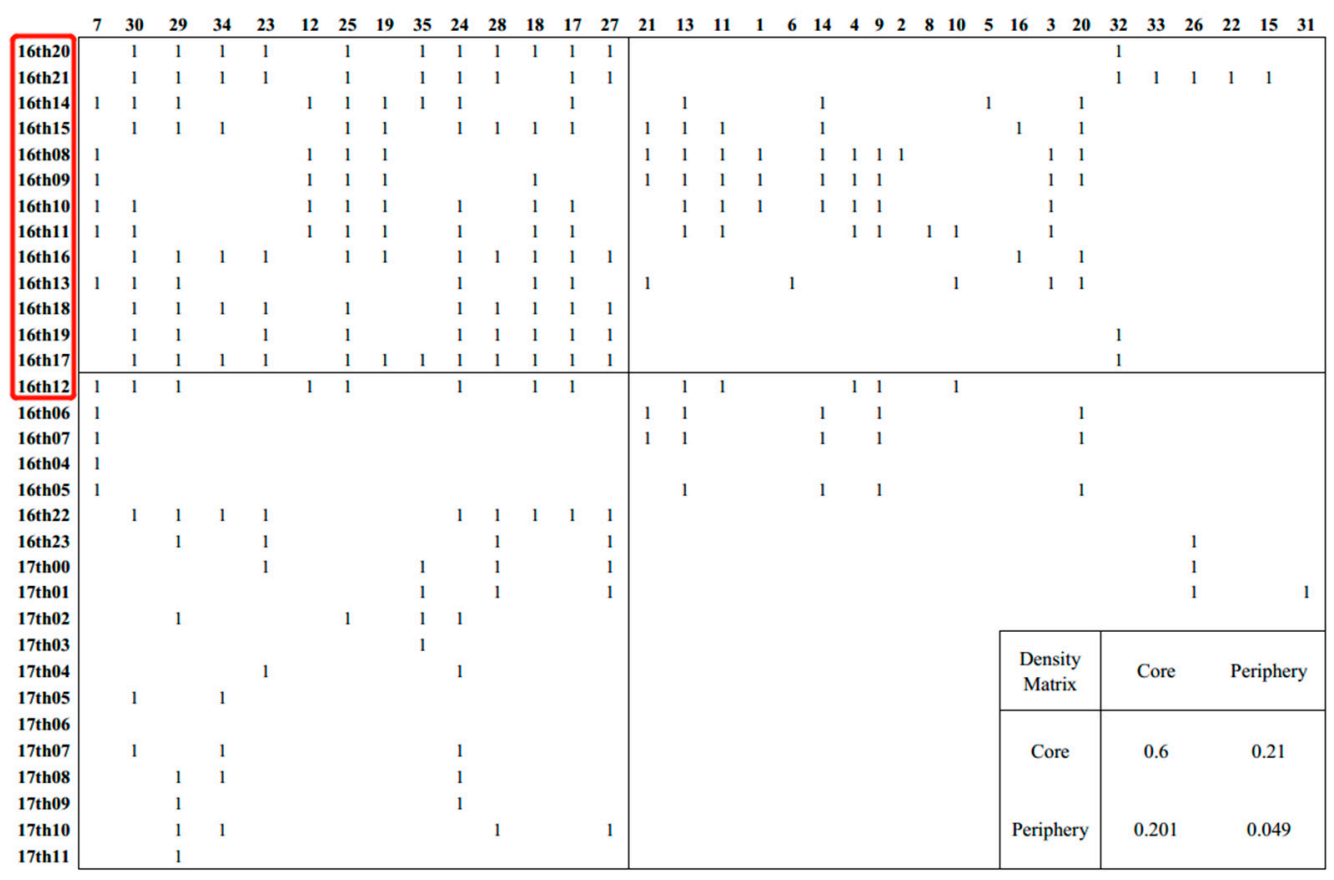

Figure 8. Core-periphery classification matrix of disaster network. Note: There are $13 \mathrm{~h}$ in core block that also belong to the "peak time period". 


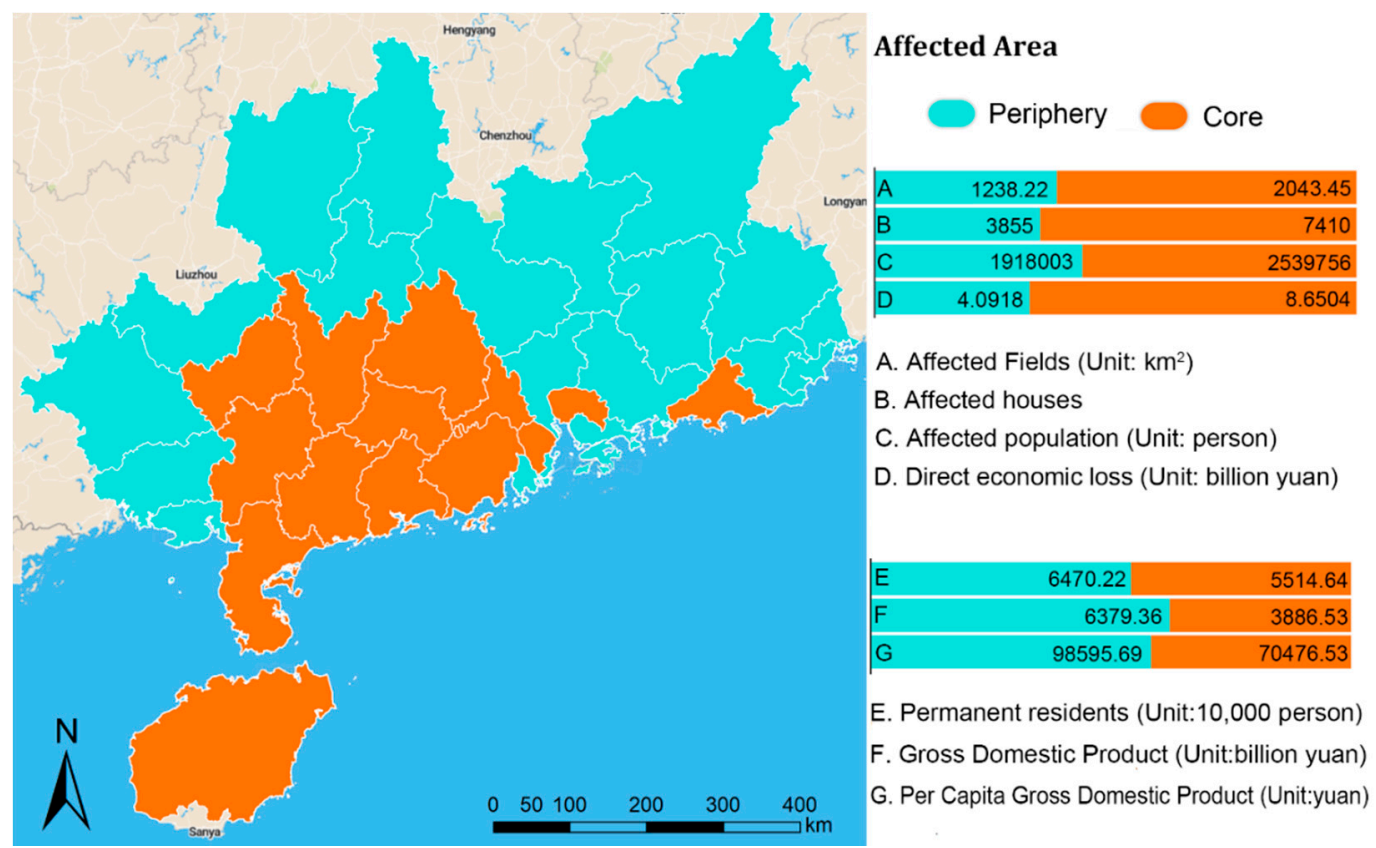

Figure 9. Comparison between core and periphery affected areas of Typhoon Mangkhut.

\subsection{Comparison between Multi-Hazards Assessment and Disaster Damage}

The disaster damages for the core and periphery areas are shown in Table 2. Approximately 4.5 million people were affected by Typhoon Mangkhut, with 2.5 million people being in the core area and 1.9 million people in the periphery area. The affected population in the core area is $32.4 \%$ higher than that in the periphery area. Typhoon Mangkhut also destroyed more than $3000 \mathrm{~km}^{2}$ of farmland and 11,000 houses, and the direct economic loss was 12.7 billion Yuan (i.e., 1.9 billion USD). The impact on the core area was greater than on the periphery area $(70 \%$ vs. $55 \%$ of the population affected, respectively), with double the loss of farmland and buildings and direct economic loss. The economic loss in the core area was estimated to be $0.22 \%$, which was almost quadruple that in the periphery area.

Table 2. Disaster damage by Typhoon Mangkhut in both core and periphery affected areas. Notes: Excludes damages of Hong Kong and Macao. The exchange rate: 1 dollar $=6.7$ yuan. Total permanent residents and GDP was 2016.

\begin{tabular}{ccccccc}
\hline & $\begin{array}{c}\text { Affected } \\
\text { Population } \\
\text { (Person) }\end{array}$ & $\begin{array}{c}\text { Percentage of the } \\
\text { Affected Population in } \\
\text { Permanent Residents }\end{array}$ & $\begin{array}{c}\text { Affected } \\
\text { Farmland } \\
\mathbf{( k m}^{2} \text { ) }\end{array}$ & $\begin{array}{c}\text { Affected } \\
\text { Building } \\
\text { (House) }\end{array}$ & $\begin{array}{c}\text { Direct } \\
\text { Economic Loss } \\
\text { (Billion USD) }\end{array}$ & $\begin{array}{c}\text { Percentage } \\
\text { of Loss in } \\
\text { GDP }\end{array}$ \\
\hline $\begin{array}{c}\text { Core } \\
\text { Periphery }\end{array}$ & $2,539,756$ & $69.68 \%$ & 2043.45 & 7410 & 1.2911 & $0.22 \%$ \\
Total & $1,918,003$ & $55.58 \%$ & 1238.22 & 3855 & 0.6107 & $0.06 \%$ \\
\hline
\end{tabular}

\section{Discussion}

Based on the results of centrality degree measurement and core-periphery analysis, the interaction between gale and heavy rain has a continuous influence on both spatial and temporal scales. For example, the multi-hazards' impact from Typhoon Mangkhut did not distribute evenly in each hour. Similarly to other tropical cyclone events that have impacted China, there was only one "peak time period" during Typhoon Mangkhut, based on centrality degree measure result in the time dimension, meaning that the influence of multi-hazards was most powerful during those $15 \mathrm{~h}$, which started $9 \mathrm{~h}$ before Typhoon Mangkhut reached landfall in China, and ended $5 \mathrm{~h}$ after landfall in China. 
Based on the classification of tropical cyclones from NMC, Typhoon Mangkhut was a severe typhoon in the first $12 \mathrm{~h}$ of "peak time period", and then the intensity of Typhoon Mangkhut decreased, and it became a typhoon in the last $3 \mathrm{~h}$ of "peak time period". The impact of Typhoon Mangkhut was evenly distributed in each city. Those core cities in the Southwest Guangdong Province and Southeast Guangxi Province suffered more from Typhoon Mangkhut, based on the core-periphery analysis result. The higher clustering coefficient of disaster network in both time and spatial dimensions, and the details of path length analysis (Table 3), also supports the strong connection between each hour and each city; there were 634 paths where the length was 1, and 296 paths where the length was 2 in the time dimension, where $63.9 \%$ and $29.8 \%$ of nodes, respectively, could connect to each other directly or by one intermediate node in the time dimension. The same situation was prevalent in the spatial dimension, which had almost $60 \%$ of nodes that could connect each other directly.

Table 3. Distance analysis of disaster network in both the time dimension and spatial dimension.

\begin{tabular}{ccccc}
\hline \multirow{2}{*}{ Value of Path Length } & \multicolumn{2}{c}{ Time Dimension } & \multicolumn{2}{c}{ Spatial Dimension } \\
\cline { 2 - 5 } & Frequency & Probability & Frequency & Probability \\
\hline $\mathbf{1}$ & 634 & $63.9 \%$ & 722 & $60.7 \%$ \\
$\mathbf{2}$ & 296 & $29.8 \%$ & 452 & $38 \%$ \\
Other & 62 & $6.3 \%$ & 16 & $1.3 \%$ \\
\hline
\end{tabular}

The result, which coupled disaster network result and disaster statistics, validated that the core-periphery classification method of disaster network is scientific and efficient. The economic statistics show that the periphery area had a larger population, higher GDP, and higher GDP per capita in 2016. This is likely because there are some megacities, such as Shenzhen, Hong Kong, Macao, and Guangzhou, within the periphery area. However, based on the disaster damage records, the population, houses, farmland, and direct economic loss were more greatly affected in the core area. Although there is a gap of disaster reduction facilities and infrastructure between the core area and periphery areas, the influence of multi-hazards still plays a more important role in attribution to disaster damages. Therefore, classifying the core areas scientifically and efficiently is essential for disaster reduction and disaster damage assessment.

Heavy rain and gales also induced a huge urban flood and impacted urban stormwater management. For example, one of the most impacted cities, Yangjiang, suffered from a flood disaster during Typhoon Mangkhut. There were two key factors in this flood disaster. One was heavy rain in Yangjiang: The artificial drainage system could not manage so much precipitation in a short period of time. The other reason was the fallen trees destroyed by the gale: These trees blocked the upper reaches of MoYangJiang, thus reducing the drainage ability of the natural drainage system. Both the artificial and natural drainage systems were influenced by heavy rain and gales; the urban stormwater management system in Yangjiang was changed deeply during Typhoon Mangkhut. This compound of extreme events induced 0.17 billion USD of direct economic losses in Yangjiang, which was the third highest city in the core region.

The contribution of this research is not only limited to identify the most severe time period and areas impacted by the Typhoon Mangkhut; it also aims to verify that a complex network methodology could be employed in multi-hazards assessment research, especially in tropical cyclone assessment. Those previous studies, which focused on natural hazards and dynamic mechanisms, and are based on complex network methodology, mostly highlight single-hazard analysis or slow-onset disasters, which are supported by long-term observed records and longer interval records (like daily or monthly data). However, with the development of data collection and management methodology, it is possible to employ the shorter interval data into rapid onset disaster assessment research, and with the assistance of data and methodology, the multi-hazards assessment of short-term disaster could be quick, scientific, and effective. The complex network could be employed not only in post-disaster assessment but also in pre-disaster prevention, with forecast data. If we change the input dataset from observed records and 
remote sensing data into typhoon forecast data and rainfall forecast data, we can establish a disaster network for incoming tropical cyclones and discover the core area of incoming disasters. This way, we can provide a scientific warning to decision-makers of disaster relief as quickly as possible.

There are two main limitations to this study. First, the validation of the multi-hazards' impact in the core area and the periphery area in spatial dimension was successful based on the disaster damage records in different cities. However, it is difficult and not realistic to collect hourly disaster damage records during typhoon events; thus, the core-periphery classification in time dimension was not able to be validated without detailed hourly damage records. Second, the multi-hazards assessment, which coupled only two kinds of hazards (gales and heavy rain), was quick and efficient in this research. However, to give an integrated evaluation of multiple hazards from tropical cyclones, more compound events should be considered, such as extreme sea levels (e.g., high astronomical tide, storm surge, and sea-level rise), which could lead to a more complex network structure. Future studies should focus on coupling three or four kinds of hazards together and discovering the mechanism of compound extreme events based on a more scientific complex network methodology.

\section{Conclusions}

In this research, a multi-hazards assessment methodology based on the bipartite network was employed in the case study of Typhoon Mangkhut in China. Results show that (1) establishing a disaster network based on complex network and the bipartite network is a scientific and effective method in the multi-hazards assessment of tropical cyclones. With the remote sensing precipitation dataset from the GEE website and the windspeed data from the China Meteorological Administration, which could be collected a few days after tropical cyclone disaster, the area that suffered from huge compound events could be found quickly and easily. (2) There was only one "peak time period", from $08 \mathrm{~h} 00$ to $22 \mathrm{~h} 00$ on 16th September, around the landfall time of China, which is $17 \mathrm{~h} 00$ on 16 th September. In addition, the core area, which includes the southwest of Guangdong, the southeast of Guangxi, and Hainan, suffered severely from multi-hazards from Typhoon Mangkhut. These cities are nearest to the typhoon center of each time. (3) The urban stormwater management system in Yangjiang was influenced by heavy rain and gales from Typhoon Mangkhut, which induced more economic losses by the flood disaster in Yangjiang.

Author Contributions: Data curation, Y.N.; Formal analysis, Y.N.; Funding acquisition, J.F. and R.C.; Investigation, Y.N.; Methodology, Y.N. and J.F.; Project administration, J.F. and R.C.; Resources, J.F.; Software, Y.N. and Z.X.; Supervision, R.C.; Validation, Y.N.; Visualization, Y.N., Z.X. and H.X.; Writing-original draft, Y.N.; Writing-review and editing, Y.N., J.F., R.C. and H.X. All authors have read and agreed to the published version of the manuscript.

Funding: This research was funded by the Ministry of Science and Technology of the People's Republic of China (Grant No. 2017YFC1503001), the Shanghai Sailing Program (No. 19YF1413700), the China Postdoctoral Science Foundation (No. 2019M651429), the National Social Science Fund of China (20ZDA085), the National Natural Science Foundation of China (Grant No. 41771119 \& 41701186), the Research Fund of the Geological Mineral Resources and Environmental Exploration Program (DD20190427), and funding from Institute of Eco-Chongming (IEC).

Conflicts of Interest: The authors declare no conflict of interest.

\section{References}

1. Kelman, I. Climate Change and the Sendai Framework for Disaster Risk Reduction. Int. J. Disaster Risk Sci. 2015, 6, 117-127. [CrossRef]

2. Pelling, M.; Maskrey, A.; Ruiz, P.; Hall, P.; Peduzzi, P.; Dao, Q.-H.; Mouton, F.; Herold, C.; Kluser, S. Reducing Disaster Risk: A Challenge for Development; John S. Swift Co.: New York, NY, USA, 2004. Available online: http://archive-ouverte.unign.ch/unige:77865 (accessed on 18 January 2004).

3. WEF. The Global Risk Report 2019 Retrieved from Geneva. Available online: http://www3.weforum.org/ docs/WEF_Global_Risks_Report_2019.pdf (accessed on 15 January 2019). 
4. Fang, J.; Liu, W.; Yang, S.; Brown, S.; Nicholls, R.J.; Hinkel, J.; Shi, X.; Shi, P. Spatial-temporal changes of coastal and marine disasters risks and impacts in Mainland China. Ocean Coast. Manag. 2017, 139, 125-140. [CrossRef]

5. Shi, P. Natural disasters in China. IHDP/Future Earth-Integrated Risk Governance Project Series; Springer: Berlin/Heidelberg, Germany, 2016; pp. 26-30.

6. Webster, P.J.; Holland, G.J.; Curry, J.A.; Chang, H.-R. Changes in Tropical Cyclone Number, Duration, and Intensity in a Warming Environment. Science 2005, 309, 1844-1846. [CrossRef] [PubMed]

7. Jeong, H.; Tombor, B.; Albert, R.; Oltvai, Z.N.; Barabási, A.-L. The large-scale organization of metabolic networks. Nature 2002, 407, 651-654. [CrossRef] [PubMed]

8. Aryal, Y.N.; Villarini, G.; Zhang, W.; Vecchi, G.A. Long term changes in flooding and heavy rainfall associated with North Atlantic tropical cyclones: Roles of the North Atlantic Oscillation and El Niño-Southern Oscillation. J. Hydrol. 2018, 559, 698-710. [CrossRef]

9. Wahl, T.; Jain, S.; Bender, J.; Meyers, S.D.; Luther, M.E. Increasing risk of compound flooding from storm surge and rainfall for major US cities. Nat. Clim. Chang. 2015, 5, 1093-1097. [CrossRef]

10. Leonard, M.; Westra, S.; Phatak, A.; Lambert, M.; van den Hurk, B.; McInnes, K.; Risbey, J.; Schuster, S.; Jakob, D.; Stafford-Smith, M. A compound event framework for understanding extreme impacts. Wiley Interdiscip. Rev. Clim. Chang. 2014, 5, 113-128. [CrossRef]

11. Chen, W.; Lu, Y.; Sun, S.; Duan, Y.; Leckebusch, G.C. Hazard Footprint-Based Normalization of Economic Losses from Tropical Cyclones in China During 1983-2015. Int. J. Disaster Risk Sci. 2018, 9, 195-206. [CrossRef]

12. Fischer, T.; Su, B.; Wen, S. Spatio-Temporal Analysis of Economic Losses from Tropical Cyclones in Affected Provinces of China for the Last 30 Years (1984-2013). Nat. Hazards Rev. 2015, 16, 04015010. [CrossRef]

13. Hoque, M.A.-A.; Phinn, S.; Roelfsema, C.; Childs, I. Assessing tropical cyclone risks using geospatial techniques. Appl. Geogr. 2018, 98, 22-33. [CrossRef]

14. Adger, W.N.; Hughes, T.P.; Folke, C.; Carpenter, S.R.; Rockström, J. Social-ecological resilience to coastal disasters. Science 2005, 309, 1036-1039. [CrossRef] [PubMed]

15. McGranahan, G.; Balk, D.; Anderson, B. The rising tide: Assessing the risks of climate change and human settlements in low elevation coastal zones. Environ. Urban. 2007, 19, 17-37. [CrossRef]

16. Nicholls, R.J.; Cazenave, A. Sea-Level Rise and Its Impact on Coastal Zones. Science 2010, 328, $1517-1520$. [CrossRef] [PubMed]

17. Woodruff, J.D.; Irish, J.L.; Camargo, S.J. Coastal flooding by tropical cyclones and sea-level rise. Nature 2013, 504, 44-52. [CrossRef]

18. Qi, P.; Du, M. Multi-factor evaluation indicator method for the risk assessment of atmospheric and oceanic hazard group due to the attack of tropical cyclones. Int. J. Appl. Earth Obs. Geoinf. 2018, 68, 1-7. [CrossRef]

19. Ferrario, F.; Beck, M.W.; Storlazzi, C.D.; Micheli, F.; Shepard, C.C.; Airoldi, L. The effectiveness of coral reefs for coastal hazard risk reduction and adaptation. Nat. Commun. 2014, 5. [CrossRef]

20. Ying, M.; Zhang, W.; Yu, H.; Lu, X.; Feng, J.; Fan, Y.; Zhu, Y.; Chen, D. An overview of the China Meteorological Administration tropical cyclone database. J. Atmos. Ocean. Technol. 2014, 31, 287-301. [CrossRef]

21. Cao, W.; Wong, M.H. Current status of coastal zone issues and management in China: A review. Environ. Int. 2007, 33, 985-992. [CrossRef]

22. Xu, S.; Wang, J.; Shi, C.; Yan, J. Research of the Natural Disaster Risk on Coastal Cities. Acta Geogr. Sin. 2006, 61, 127-138.

23. Miller, J.D.; Kim, H.; Kjeldsen, T.R.; Packman, J.; Grebby, S.; Dearden, R. Assessing the impact of urbanization on storm runoff in a peri-urbancatchment using historical change in impervious cover. J. Hydrol. 2014, 515, 59-70. [CrossRef]

24. Fletcher, T.D.; Andrieu, H.; Hamel, P. Understanding, management and modelling of urban hydrology and its consequences for receiving waters: A state of the art. Adv. Water Resour. 2013, 51, 261-279. [CrossRef]

25. Zhang, K.; Xiao, C.; Shen, J. Comparison of the CEST and SLOSH Models for Storm Surge Flooding. J. Coast. Res. 2008, 24, 489-499. [CrossRef]

26. Lin, N.; Kopp, R.E.; Horton, B.P.; Donnelly, J.P. Hurricane Sandy's flood frequency increasing from year 1800 to 2100. Proc. Natl. Acad. Sci. USA 2016, 113, 12071-12075. [CrossRef] [PubMed]

27. Ye, Y.; Fang, W. Estimation of the compound hazard severity of tropical cyclones over coastal China during 1949-2011 with copula function. Nat. Hazards 2018, 93, 887-903. [CrossRef] 
28. Gettelman, A.; Bresch, D.N.; Chen, C.C.; Truesdale, J.E.; Bacmeister, J.T. Projections of future tropical cyclone damage with a high-resolution global climate model. Clim. Chang. 2018, 146, 575-585. [CrossRef]

29. Tsuboki, K.; Yoshioka, M.K.; Shinoda, T.; Kato, M.; Kanada, S.; Kitoh, A. Future increase of supertyphoon intensity associated with climate change. Geophys. Res. Lett. 2015, 42, 646-652. [CrossRef]

30. Landsea, C.W.; Harper, B.A.; Hoarau, K.; Knaff, J.A. Can We Detect Trends in Extreme Tropical Cyclones? Science 2006, 313, 452-454. [CrossRef]

31. Brun, J.; Barros, A.P. Mapping the role of tropical cyclones on the hydroclimate of the southeast United States: 2002-2011. Int. J. Climatol. 2014, 34, 494-517. [CrossRef]

32. Chen, F.; Fu, Y. Contribution of tropical cyclone rainfall at categories to total precipitation over the Western North Pacific from 1998 to 2007. Sci. China Earth Sci. 2015, 58, 2015-2025. [CrossRef]

33. Czajkowski, J.; Villarini, G.; Montgomery, M.; Michel-Kerjan, E.; Goska, R. Assessing Current and Future Freshwater Flood Risk from North Atlantic Tropical Cyclones via Insurance Claims. Sci. Rep. $2017,7$. [CrossRef]

34. Zhang, Q.; Lai, Y.; Gu, X.; Shi, P.; Singh, V.P. Tropical Cyclonic Rainfall in China: Changing Properties, Seasonality, and Causes. J. Geophys. Res. Atmos. 2018, 123, 4476-4489. [CrossRef]

35. Kappes, M.S.; Keiler, M.; von Elverfeldt, K.; Glade, T. Challenges of analyzing multi-hazard risk: A review. Nat. Hazards 2012, 64, 1925-1958. [CrossRef]

36. Asprone, D.; Jalayer, F.; Prota, A.; Manfredi, G. Proposal of a probabilistic model for multi-hazard risk assessment of structures in seismic zones subjected to blast for the limit state of collapse. Struct. Saf. 2010, 32, 25-34. [CrossRef]

37. Boers, N.; Goswami, B.; Rheinwalt, A.; Bookhagen, B.; Hoskins, B.; Kurths, J. Complex networks reveal global pattern of extreme-rainfall teleconnections. Nature 2019, 566, 373-377. [CrossRef] [PubMed]

38. Gill, J.C.; Malamud, B.D. Reviewing and visualizing the interactions of natural hazards. Rev. Geophys. 2014, 52, 680-722. [CrossRef]

39. Li, N.; Liu, X.; Xie, W.; Wu, J.; Zhang, P. The Return Period Analysis of Natural Disasters with Statistical Modeling of Bivariate Joint Probability Distribution. Risk Anal. 2013, 33, 134-145. [CrossRef]

40. Lozoya, J.P.; Sardá, R.; Jiménez, J.A. A methodological framework for multi-hazard risk assessment in beaches. Environ. Sci. Policy 2011, 14, 685-696. [CrossRef]

41. Chorozoglou, D.; Kugiumtzis, D.; Papadimitriou, E. Application of complex network theory to the recent foreshock sequences of Methoni (2008) and Kefalonia (2014) in Greece. Acta Geophys. 2017, 65, 543-553. [CrossRef]

42. Daskalaki, E.; Spiliotis, K.; Siettos, C.; Minadakis, G.; Papadopoulos, G.A. Foreshocks and short-term hazard assessment of large earthquakes using complex networks: The case of the 2009 L'Aquila earthquake. Nonlinear Process. Geophys. 2016, 23, 241-256. [CrossRef]

43. Evaggelidis, I.N.; Siettos, C.I.; Russo, P.; Russo, L. Complex network theory criterion to distribute fuel breaks for the hazard control of fire spread in forests. AIP Conf. Proc. 2015, 1648, 100005.

44. Konapala, G.; Mishra, A. Review of complex networks application in hydroclimatic extremes with an implementation to characterize spatio-temporal drought propagation in continental USA. J. Hydrol. 2017, 555, 600-620. [CrossRef]

45. Xu, X.; Wang, C.; Cai, C.; Xue, M. Evolution and coping research for flood disaster social stability risk based on the complex network. Nat. Hazards 2015, 77, 1491-1500. [CrossRef]

46. Chan, E.Y.Y.; Man, A.Y.T.; Lam, H.C.Y.; Chan, G.K.W.; Hall, B.J.; Hung, K.K.C. Is urban household emergency preparedness associated with short-term impact reduction after a super typhoon in subtropical city? Int. J. Environ. Res. Public Health 2019, 16, 596. [CrossRef] [PubMed]

47. Boykoff, M.; Katzung, J.; Nacu-Schmidt, A. Media and Climate Change Observatory Monthly Summary-Issue 21. September 2018. Available online: https://sciencepolicy.colorado.edu/icecaps/research/ media_coverage/summaries/issue21.html (accessed on 1 October 2018).

48. Choy, C.; Wu, M. A Wake up Call from Mangkhut. Available online: https://www.hko.gov.hk/en/blog/ 00000216.htm (accessed on 29 October 2018).

49. Schembri, F. Deadly storms break records, damage facilities. Science 2018, 361, 1172-1173. [CrossRef] [PubMed] 
50. Kubota, T.; Shige, S.; Hashizume, H.; Aonashi, K.; Takahashi, N.; Seto, S.; Hirose, M.; Takayabu, Y.; Ushio, T.; Nakagawa, K. Global precipitation map using satellite-borne microwave radiometers by the GSMaP project: Production and validation. IEEE Trans. Geosci. Remote Sens. 2007, 45, 2259-2275. [CrossRef]

51. Shige, S.; Watanabe, T.; Sasaki, H.; Kubota, T.; Kida, S.; Okamoto, K. Validation of western and eastern Pacific rainfall estimates from the TRMM PR using a radiative transfer model. J. Geophys. Res. Atmos. 2008, 113. [CrossRef]

52. Erdős, P.; Rényi, A. On the evolution of random graphs. Publ. Math. Inst. Hung. Acad. Sci. 1960, 5, 17-60.

53. Watts, D.J. The "new" science of networks. Annu. Rev. Sociol. 2004, 30, 243-270. [CrossRef]

54. Albert, R.; Jeong, H.; Barabási, A.-L. Internet: Diameter of the world-wide web. Nature 1999, 401, $130-131$. [CrossRef]

55. Liljeros, F.; Edling, C.R.; Amaral, L.A.N.; Stanley, H.E.; Åberg, Y. The web of human sexual contacts. Nature 2001, 411, 907-908. [CrossRef]

56. Williams, R.J.; Berlow, E.L.; Dunne, J.A.; Barabási, A.-L.; Martinez, N.D. Two degrees of separation in complex food webs. Proc. Natl. Acad. Sci. USA 2002, 99, 12913-12916. [CrossRef] [PubMed]

57. Albert, R.; Barabási, A.-L. Statistical mechanics of complex networks. Rev. Mod. Phys. 2002, 74, 47. [CrossRef]

58. Latapy, M.; Magnien, C.; Vecchio, N.D. Basic notions for the analysis of large two-mode networks. Soc. Netw. 2008, 30, 31-48. [CrossRef]

59. Scott, J.; Carrington, P.J. The SAGE Handbook of Social Network Analysis; SAGE Publications Inc.: London, UK, 2011.

60. Watts, D.J.; Strogatz, S.H. Collective dynamics of 'small-world' networks. Nature 1998, 393, 440-442. [CrossRef]

(C) 2020 by the authors. Licensee MDPI, Basel, Switzerland. This article is an open access article distributed under the terms and conditions of the Creative Commons Attribution (CC BY) license (http://creativecommons.org/licenses/by/4.0/). 